\title{
A fuga de cérebros em Portugal: hipóteses explicativas
}

\author{
Brain drain in Portugal: explanatory hypotheses \\ La fuga de cerebros en Portugal: hipótesis explicativas \\ LUÍSA CERDEIRA \\ BELMIRO CABRITO \\ MARIA DE LOURDES MACHADO TAYLOR \\ RUI GOMES
}

\begin{abstract}
Resumo: Neste artigo apresenta-se uma investigação em curso em Portugal sobre a emigração de portugueses altamente qualificados na última década. Nesse estudo, pioneiro em Portugal analisa-se: 1) quais são as modalidades e as características da fuga de cérebros em Portugal? 2) Quais as formas de articulação entre as diferentes modalidades do êxodo de competências português e o processo das migrações internacionais? 3) Quais as formas de articulação entre a fuga de cérebros e o crescente fluxo de mobilidade académica? 4) Quais são as principais causas do brain drain em Portugal na última década.
\end{abstract}

Palavras-chave: Emigração qualificada; mobilidade académica; redes.

Abstract: This paper presents an ongoing research study in Portugal on the emigration of highly skilled Portuguese citizens over the last decade. In this pioneering study in Portugal the following issues are analysed: 1) What are the modes and characteristics of the brain drain in Portugal? 2) What are the forms of articulation between the different modes of Portuguese skills exodus and the process of international migrations? 3) What are the forms of articulation between the brain drain and the increasing academic mobility flow? 4) What are the main causes of the brain drain in Portugal over the last decade?

Keywords: Skilled emigration; academic mobility; networks.

Resumen: En este artículo presentamos una investigación en curso en Portugal sobre la emigración de portugueses altamente cualificados en la última década. En este estudio pionero en Portugal se analizaron: 1) ¿Cuáles son los términos y características de la fuga de cerebros en Portugal? 2) ¿Qué formas de coordinación entre los diferentes modos de éxodo de competencias portugués y el proceso de las migraciones internacionales? 3) ¿Qué formas de articulación entre la fuga de cerebros y el flujo de la creciente movilidad académica? 4) ¿Cuáles son las principales causas de la fuga de cerebros en Portugal en la última década?

Palabras clave: Emigración calificada; movilidad académica; redes. 


\section{INTRODUÇÃO}

Um dos problemas com que alguns países se deparam é, certamente, o da emigração de indivíduos portadores de elevadas qualificações académicas e profissionais. Essa é situação urgente a ser estudada e combatida quando ocorre dos países menos desenvolvidos para os mais desenvolvidos, dado que essa emigração de profissionais altamente qualificados deixa as economias dos países menos desenvolvidos com oferta reduzida de pessoas qualificadas na investigação, na produção e nos serviços públicos e privados.

Naturalmente, esse tipo de emigração ainda se torna mais problemático porque corresponde a uma fuga de cérebros que limita o retorno do investimento educacional dos países de envio, criando condições favoráveis para sua utilização pelos países mais desenvolvidos. Numa palavra, a fuga de cérebros significa que os países receptores vão beneficiar-se de capital humano altamente qualificado a custo zero.

Embora as estatísticas existentes sobre esse tipo de emigração ainda sejam bastante precárias na metodologia usada e limitadas no seu alcance, é reconhecido em estudos internacionais publicados nos últimos anos que Portugal é um dos países europeus em que a fuga de cérebros mais se acentuou na última década.

Docquier e Marfouk (2007) estimavam em 19,5\% a proporção de trabalhadores com grau académico superior que emigraram nos últimos anos e que Portugal teria perdido $1 / 5$ da sua força de trabalho mais qualificada.

O Gráfico 1 dá a conhecer os números da emigração porrtuguesa para os países mais escolhidos. 


\section{GRÁFICO 1}

Os dez países com mais portugueses emigrados, 2001-2011

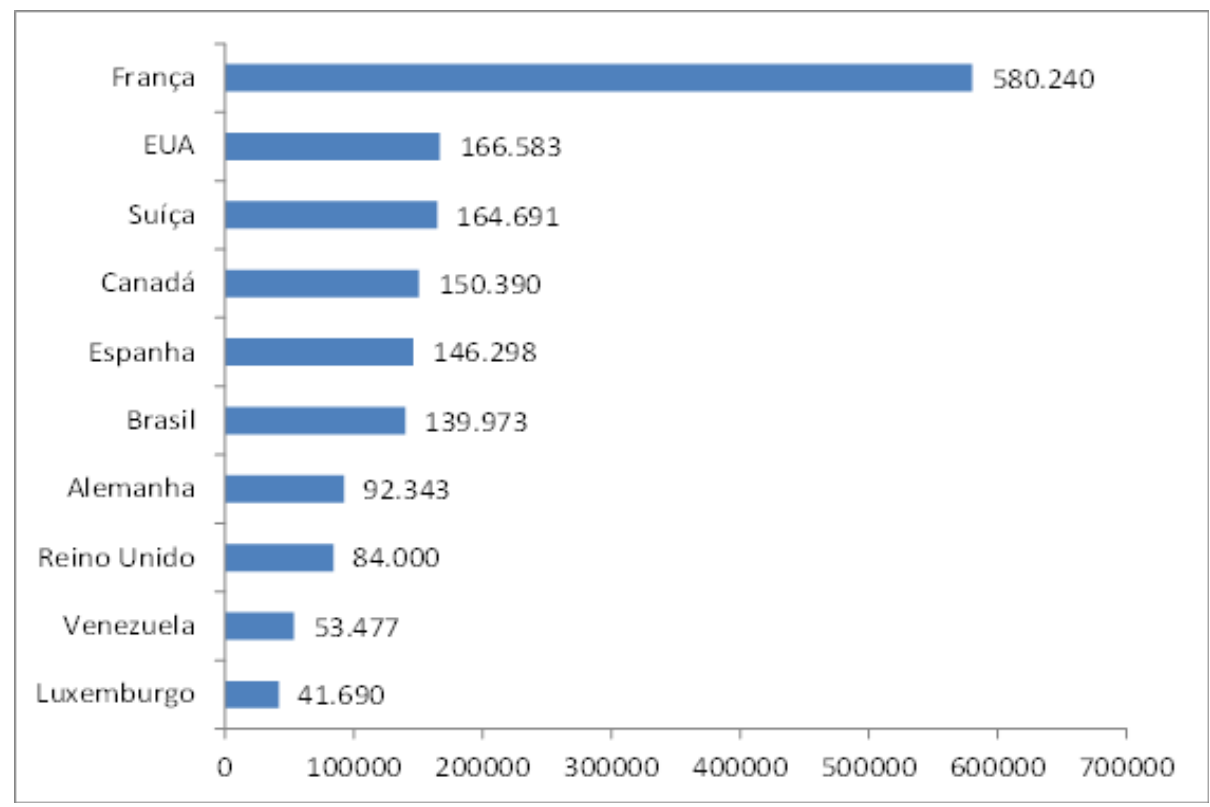

Fonte: Observatório da Emigração; atualizado em 24/01/2013

Para além dos números elevados que nossa emigração tem vindo a atingir na última década, é de enorme importância perceber como se tem comportado a emigração qualificada, exactamente pelos problemas que poderá acarretar ao país e que permite equacionar se o país está, ou não, a conhecer um processo de "fuga de cérebros" (ver Tabela 1).

Tabela 1: Evolução da população emigrante em Portugal, com mais de 15 anos, na OCDE

\begin{tabular}{|c|c|c|c|c|c|}
\hline Período & \multicolumn{3}{|c|}{ População emigrante } & \multicolumn{2}{c|}{ Taxa de emigração } \\
\hline & $\begin{array}{c}\text { Total (em } \\
\text { milhares) }\end{array}$ & $\begin{array}{c}\text { Altamente } \\
\text { qualificada }(\mathrm{em} \\
\text { milhares) }\end{array}$ & $\begin{array}{c}\text { Altamente } \\
\text { qualificada } \\
(\mathrm{em} \%)\end{array}$ & $\begin{array}{c}\text { Taxa de } \\
\text { emigração total } \\
(\%)\end{array}$ & $\begin{array}{c}\text { Taxa de emigração } \\
\text { da população } \\
\text { altamente qualificada } \\
\text { (em \%) }\end{array}$ \\
\hline $\mathbf{2 0 0 0}$ & 1260.8 & 81 & 6.4 & 12.8 & 8.0 \\
\hline $\mathbf{2 0 0 5 - 2 0 0 6}$ & 1382.1 & 119 & 8.6 & 13.5 & 11.6 \\
\hline $\mathbf{2 0 1 0 - 2 0 1 1}$ & 1492.0 & 147 & 9.9 & 14.2 & 12.9 \\
\hline
\end{tabular}

Fonte: http://www.oecd.org/els/mig/dio.htm

Os números do quadro acima são bem reveladores da forma como tem crescido a emigração altamente qualificada em Portugal, obrigando a uma reflexão cuidada sobre o tema. Essa evolução crescente da emigração altamente qualificada 
ainda se torna mais perceptível nos seus contornos quando se comparam o crescimento relativo da emigração total e da emigração altamente qualificada ao longo do período. Observe-se a Tabela 2:

Tabela 2

Crescimento percentual da população emigrante (total e altamente qualificada) no período 2000-2011

\begin{tabular}{|c|c|c|}
\hline Periodo & População emigrante total (\%) & $\begin{array}{c}\text { População emigrante altamente } \\
\text { qualificada (\%) }\end{array}$ \\
\hline $\mathbf{2 0 0 6 - 2 0 1 1}$ & 8 & 24 \\
\hline $\mathbf{2 0 0 0 - 2 0 1 1}$ & 18 & 82 \\
\hline
\end{tabular}

Fonte: http://www.oecd.org/els/mig/dio.htm

A análise dos valores no Quadro 2 mostra bem que a emigração portuguesa cresceu entre 2000 e 2011, mas que, mais acentuado na população altamente qualificada, esse crescimento evidencia um processo real de fuga de cérebros do país.

É nesse quadro de descapitalização intelectual e profissional do país que se leva a cargo a investigação Projecto "BRADAMO - Brain Drain and Academic Mobility from Portugal to Europe", financiado pela Fundação para a Ciência e Tecnologia.

\section{QUADRO TEÓRICO E METODOLÓGICO DA INVESTIGAÇÃO}

A emigração altamente qualificada tem vindo a ser analisada de acordo com dois modelos contrastantes: a) êxodo - sublinha a ideia de que os indivíduos mais qualificados são forçados para o exílio, permitindo-lhes obter emprego e remuneração correspondentes à sua formação; b) diáspora - salienta os benefícios mútuos de intercâmbio intercultural aberto pela circulação de elites cosmopolitas académicas, científicas e culturais.

Esta investigação pretende pôr à prova o poder analítico e explicativo de cada uma destas teses, tomando como referência os vários tipos de emigração de portugueses altamente qualificados, na última década, para a Europa.

Articulando uma investigação extensiva com uma análise em profundidade, intensiva, procura-se identificar a subjetividade dos atores diretos da emigração em alguns dos seus principais contextos de trabalho.

Para tal, utiliza-se uma estratégia mista que recorre a técnicas quantitativas e qualitativas de recolha de informação: a) inquéritos por questionário, com vista à caracterização dos factores de atracção e repulsão presentes na decisão de emigrar, bem como os efeitos de deskilling and reskilling resultantes da migração; b) 
histórias de vida e entrevistas a focus groups, que caracterizarão os projectos de vida, as trajectórias, os efeitos socializadores e as estratégias de rentabilização do capital escolar.

Será um estudo de caso múltiplos que tem por objectivos descrever e comparar as circunstâncias, as modalidades e as características dos fluxos de mobilidade europeia altamente qualificada de dois tipos de migração: a) migração de longo prazo para um país europeu para trabalhar no segmento primário ou secundário do sistema de emprego; b) mobilidade temporária e circulação transitória ou pendular através de redes europeias de ciência, produção, serviços ou cultura.

A investigação parte da hipótese teórica de que a migração de diferentes fluxos, bem como os contextos, os projetos, os caminhos da vida e como as expectativas de vida são construídos, podem ser compreendidos por cinco modelos contrastantes: a hipótese da fuga de cérebros. Dado que o capital humano não é rentabilizado na mesma sociedade ou país onde foi gerado, há uma perda do capital investido na formação desses indivíduos (HAMILTON, 2003; CASTLES; MILLER, 2003); a hipótese de uma fuga de cérebros benéfica. Dado que a emigração de indivíduos qualificados resulta em maior rendimento individual, o que é possibilitado através do seu investimento em educação; então, mais indivíduos estarão disponíveis para investir na sua educação e dos seus filhos e isto irá eventualmente aumentar a taxa de retorno à educação nos países em desenvolvimento (BEINE; DOCQUIER; RAPOPORT, 2003, 2008; DOCQUIER; MARFOUK., 2007); a hipótese da "fertilização" cruzada das elites. O movimento internacional de recursos humanos qualificados é muitas vezes transitório e assume características de troca de conhecimentos, habilidades e projetos temporários; este processo circular é benéfico para ambos os países desenvolvidos e países em desenvolvimento (OLESEN, 2002); a hipótese da circulação de brain drain através da criação de redes. As redes transnacionais científicas e de negócios com vista à transferência dos resultados de tecnologia e conhecimentos, provenientes dos países de acolhimento para os países de origem (MEYER, 2001); a hipótese da fuga de cérebros latente durante a mobilidade formativa. Com a mobilidade de formação para estudos graduados ou pósgraduados, que se acentuou na última década, as saídas para estudar no exterior, com ou sem bolsa, originalmente planeadas como temporárias, podem tornar-se permanentes, devido à inserção no mercado de trabalho dos países desenvolvidos (PIZARRO, 2005). 


\section{RESULTADOS PRELIMINARES}

Nesta comunicação apresentam-se alguns dos resultados já obtidos e conseguidos a partir das entrevistas já realizadas à data. Assim, analisa-se o conteúdo de entrevistas realizadas com quatro focus groups (17 indivíduos), considerando as razões apresentadas para a mobilidade dentro do espaço europeu e as características temporais de mobilidade (permanente ou temporário, a longo prazo ou transitória).

A partir dessa análise foi possível identificar:

A - Fatores de Push e Pull, respondendo à questão:

* Quais são as razões que levam os indivíduos qualificados a deixar o seu país de origem? O que existe em outros países que carece em Portugal?

Os fatores apresentados pelos entrevistados para o êxodo estão relacionados a três aspectos principais: a) a crise do mercado de trabalho em Portugal oferece poucas oportunidades para trabalho qualificado; b) o conteúdo do trabalho não usa sempre eficazmente as qualificações alcançadas e certificadas pelo sistema educacional; c) o desejo de acumular capital de internacionalização. A maioria dos entrevistados expressou a ideia de que não encontraram em Portugal a satisfação e a realização profissional ou os estímulos cognitivos e profissionais essenciais para o desenvolvimento da carreira:

Aqui em Londres sinto-me mais confortável ou mesmo mais seguro, não por causa da relação que tenho com meu empregador actual, mas sim pelo número de alternativas disponíveis no mercado. O mercado tem uma extraordinária amplitude e posso mudar sempre que eu quero, e, portanto, é uma relação completamente diferente com o trabalho. (e6. Caso D1). Quando eu estava terminando o meu programa de estudo, deixar Portugal estava completamente fora dos meus planos; Eu queria ficar em Portugal, acontecesse o que acontecesse. Depois comecei a trabalhar e vi como o mercado era na realidade, e houve um momento que eu quis superar essa barreira: "Não, eu tenho que sair, se eu quiser fazer o que gosto de fazer", e então fui-me embora. (e3. Caso D1). Por quê emigrar? Bem, há várias razões para isso; maior propensão para a aventura, especialmente a ideia de que, a fim de desenvolver uma carreira, uma carreira internacional, ou de ter visibilidade internacional na área, eu não poderia atingir isso sem um treino no estrangeiro... Do ponto de vista [da] carreira, especialmente em Portugal, eu acho que em qualquer lugar em termos [de] carreira na ciência em geral, a mobilidade é um pré-requisito para a progressão, a mobilidade é uma condição, é uma maneira de acumular capital, especialmente em Portugal, o que é extremamente forte... (e1. Caso D1).

A partir desses testemunhos, pode-se perceber que a emigração aparece 
como uma forma de "fazer o que se gosta", de desenvolver uma carreira e projetála internacionalmente. No entanto, a existência de melhores oportunidades de trabalho nos países de destino é também bastante focada; os emigrantes têm uma maior sensação de estabilidade e segurança no trabalho, na medida em que há mais opções.

B - Duração do processo migratório, Longo prazo ou Mobilidade Transitória, respondendo à questão:

* Quando uma pessoa emigra, a pessoa considera essa decisão como uma medida temporária ou de longo prazo? É um projeto para a vida ou a curto prazo?

A maioria dos entrevistados refere que a perspectiva de mobilidade é, pelo menos, de médio prazo. Embora inicialmente possa ser uma solução transitória, a experiência vivida, entretanto, mudou os planos por um maior período de migração.

Quando me perguntam se eu sempre desejei voltar para Portugal, eu digo que não, se me perguntarem que se eu quero voltar para Portugal hoje, também digo não. Se eu voltar a Portugal, necessariamente será para trabalhar nalgum lugar que eu considere como integrado numa rede internacional, entende? (e2. Caso D1). $\mathrm{Na}$ maioria das vezes que eu vim, nunca pensei que ficaria a longo prazo, porque eu sempre vim com vários empregos temporários, contratos a curto prazo e eu sabia que, em algum momento, eu teria que voltar. Neste momento em particular, gostaria de ir para Portugal, eu sinto a falta, estou longe do país há muitos anos, mas também não estou seguro de querer ficar lá para sempre... (e1. Caso D2).

A ideia de uma emigração temporária deu origem a uma emigração de longo prazo. As oportunidades encontradas, juntamente com a sensação de não conseguir o mesmo em Portugal, são as razões mais frequentemente mencionadas para essa mudança. Emigração transitória fora de Portugal é também um cenário que agora é considerado mais naturalmente.

\section{CONCLUSÕES}

1. Os factores que explicam o aumento da mobilidade europeia e da emigração são múltiplos e relacionais: a) crise do sistema de empregos qualificados em Portugal; b) poucas oportunidades para aplicar e desenvolver as competências profissionais adquiridas na educação formal e na fase de entrada profissional realizada em Portugal; c) fortes expectativas de internacionalização e a criação de redes científicas e profissionais; d) busca da autonomia pessoal; e) a construção e manutenção de relacionamentos pessoais e românticos.

2. As características temporais da mobilidade são predominantemente de 
longo ou médio prazo.

3. Os projectos de mobilidade temporária ou transitória têm-se tornado projetos de emigração de longo prazo.

4. Só razões familiares têm o potencial de perturbar as opções atuais de mobilidade.

5. Podemos concluir que os factores percepcionados como cruciais na decisão de emigrar iniciaram-se com a crise económica, a desvalorização dos recursos locais, a falta de oportunidades de carreira e o desemprego.

6. Os laços que os migrantes têm com seu país de origem ajuda a entender quando os movimentos migratórios contribuem mais para situações de ganho de brain drain ou situações de desperdício do brain drain em cada migração.

O projeto "Êxodo de Competências e Mobilidade Académica de Portugal para a Europa" (PTDC/IVC-PEC/5049/2012) é financiado por fundos nacionais através da Fundação para a Ciência e a Tecnologia (FCT/MEC) e cofinanciado pelo Fundo Europeu de Desenvolvimento Regional (FEDER), através do COMPETE - Programa Operacional Fatores de Competitividade (POFC), envolvendo investigadores das Universidades de Coimbra, Lisboa e Porto (Rui Gomes, coordenador; Luísa Cerdeira, João Teixeira Lopes, Henrique Vaz, Rui Brites, Belmiro Cabrito, Maria de Lourdes Machado-Taylor, Dulce Magalhães, Tomás Patrocínio, Paulo Peixoto, Rafaela Ganga, Sílvia Silva, José Pedro Silva).

\section{REFERÊNCIAS}

BEINE, Michel; DOCQUIER, Frédéric; RAPOPORT, Hiller. Brain drain and LDC's Growth: Winners and loosers. Discussion Paper n. 819. Bona, Alemanha, 2003.

Brain drain and human capital formation in developing countries: Winners and losers. The Economic Journal, Londres, Reino Unido, v. 118, n. 528 , p. $631-652,2008$.

CASTLES, Stephen; MILLER, Mark J. Age of Migration International Population Movements in the Modern World. Basingstoke: Palgrave Macmillan, 2003.

DOCQUIER, Frédéric; MARFOUK, Abdeslam. Brain drain in developing countries. World Bank Economic Review, Oxford, Reino Unido, v. 21, n. 2, p. 193-218, 2007.

HAMILTON, Kim. Migration and development: Blind fact and hand-to-find facts. Migration Policy Institute, Washington, Estados Unidos da América, 2003. 
Acessado em 10 de Fevereiro de 2015

http://www.migrationpolicy.org/article/migration-and-development-blindfaith-and-hard-find-facts

MEYER, Jean-Baptiste. Network approach versus brain drain: Lessons from the diaspora. International Migration, Oxford, Reino Unido e Malden (MA), Estados Unidos da América; v. 5, p. 91-110, 2001.

OLESEN, Henrik. Migration, return and development: An institutional perspective. International Migration, Oxford, Reino Unido e Malden (MA) Estados Unidos da América, v. 40, n. 4, p. 125-151, 2002.

PIZARRO, Jorge Martínez. Globalizados, pero restringidos. Una visión latinoamericana del mercado global de recursos humanos calificados. Santiago de Chile: Centro Latinoamericano y Caribeno de Demografia, 2005.

LUÍSA CERDEIRA é licenciada em Economia pela Universidade Técnica de Lisboa, Portugal. Possui mestrado em Administração Escolar pela Universidade de Évora, Portugal, e doutorado em Economia da Educação pela Universidade de Lisboa, Portugal. Atualmente é professora auxiliar da Universidade de Lisboa, Portugal.

BELMIRO CABRITO é Professor Associado Aposentado (2011) do Instituto de Educação da Universidade de Lisboa (IE-UL). Graduado em Economia (1972) e em Ciências Sociais e Políticas (1978) pela Universidade Técnica de Lisboa. Mestre (1993) e Doutor (2000) em Ciências da Educação pela Universidade de Lisboa. Coordenador do Curso de Mestrado e do Curso de Formação Avançada em Ciências da Educação-Formação de Adultos e do Curso de Mestrado em Ensino de Economia e da Contabilidade do IE-UL, até 2011. Professor de Economia da Educação e de Financiamento e Gestão da Educação e da Formação no IE-UL até 2011. Investigador no âmbito da Economia da Educação e do Financiamento do Ensino Superior. Membro e/ou Investigador Principal em projectos de investigação financiados pela FCT, pela FCT-CAPES, Fundação Calouste Gulbenkian e por fundos comunitários, nas áreas da formação profissional, do financiamento da educação e da mobilidade internacional de população altamente qualificada.

MARIA DE LOURDES MACHADO TAYLOR é graduada em Economia pela Universidade do Porto, Portugal e em Estudos Administrativos, pela Universidade do Minho, Portugal. Possui PhD em Ciências Empresariais pela Universidade do Minho, Portugal. Trabalha como pesquisadora do Centro de Investigação de Politicas do Ensino Superior (CIPES) e atualmente trabalha na Agência de Avaliação e Acreditação do Ensino Superior (A3ES)

RUI GOMES é Professor Catedrático e pesquisador do Centro de Estudos Sociais da Universidade de Coimbra. Coordena os cursos de Mestrado em Ensino da Educação Física e em Lazer e Desenvolvimento Local, bem como o curso de 
Doutoramento em Turismo, Lazer e Cultura. Tem feito pesquisa em Sociologia da Educação, incluindo a análise da mobilidade estudantil e profissional. Coordenou recentemente dois livros neste âmbito: Fuga de cérebros - Retratos da emigração portuguesa qualificada, Bertrand Editora, 2015 e Entre a periferia e o centro. Percursos de emigrantes portugueses qualificados, Imprensa da Universidade de Coimbra, 2015. Conferencista e professor visitante de universidades estrangeiras, é também autor de numerosos artigos em Sociologia das Políticas Educativas. Editou vários livros neste domínio: Culturas de Escola e Identidades dos Professores, Educa, 1993; Zeitgeschichte Europäischer Bildung 1970-2000 (Nationale Entwicklungsprofile), (em col.), Waxmann, 2000; O governo da educação em Portugal, Imprensa da Universidade de Coimbra, 2005.

Recebido em março de 2015 Aprovado em setembro de 2015 